\title{
STUDY ON EARLY RECOGNITION METHODS OF COVER- COLLAPSE SINKHOLES IN CHINA
}

\section{Long Jia}

Institute of Karst Geology, CAGS, Guilin 541004, China

Yan Meng

Key Laboratory of Karst Collapse Prevention, CAGS, Guilin 541004, China

Zong-Yuan Pan

No.50, Qixing Road

GuilCity, Guangxi Province, China, jialong@karst.ac.cn

\begin{abstract}
Cover-collapse sinkholes pose a major geohazard occurring in mantled karst regions in the south of China in recent years. Cover deposits generally mask the subsurface development and propagation of the deformation to the topographic surface. Human security and land-use planning in sinkhole-prone areas need to be preceded by detailed investigations focused on identification of pre-existing sinkholes, subsurface dissolution, subsidence features, and groundwater condition. Thefore the abnormal, early hidden danger signs (ground, underground and hydrodynamic) of karst collapse are studied. Further, the corresponding identification techniques and methods are presented, such as surface surveying techniques (satellite remote sensing, the drone, etc.), underground detection technology (ground penetrating radar, microgravity, micro tremor, etc.), and monitoring of groundwater conditions. Finally, all kinds of techniques and methods can be combined to form a comprehensive system for identifying hidden dangers of karst collapse. This paper aims at identifying the early hidden dangers of karst collapse geological disasters. This has important theoretical, technical and social significance in order to minimize the impact of disasters on the people and the environment.
\end{abstract}

\section{Introduction}

Cover-collapse sinkholes are a major geohazard occurring in soil-covered karst regions. Cover-collapse sinkhole features are the result of the water-borne transport of soil or other related material downward into underlying voids in either the limestone bedrock or the soil profile. Cover deposits generally mask the subsurface development and propagation of the deformation to the topographic surface (Beck, 2004; Waltham et al., 2005; Gutiérrez et al., 2008, 2014).

When sinkholes, including sudden catastrophic collapses and subsidence at considerable depths, may adversely interact with the human environment, multidisciplinary approaches should be planned to 1 .
Ascertain the surface subsidence and sinkhole features; 2. Locate and define precisely the subsurface dissolution and underlying subsidence features (such as karst cave, soil-cavities, the presence of active subsidence and so on); 3. Monitor groundwater conditions. Land-use planning in sinkhole-prone areas needs to be preceded by detailed investigations focused on the identification of pre-existing sinkholes, subsurface dissolution and subsidence features (Galve et al., 2009).

Karst collapses have occurred frequently in the south of China in recent years. The present study represents a contribution to monitoring and understanding the genesis and early stage evolution of a sinkhole using different methodologies.

\section{Methodology}

The multidisciplinary approach follows three aspects: 1. Surface surveying methods (field surveys, satellite remote sensing, the drone, etc.); 2. Underground detection methods (ground penetrating radar, Photoelectric monitoring, etc.); and 3. Hydrodynamic monitoring.

\section{Surface Survey Methods}

In some cases, pre-collapse surficial evidence can be identified by topographic depressions and geomorphological analyses. Field surveys and interpretation of remote-sensed imagery are often useful to identify sinkhole surface factors (Forth, et al., 1999; Kaufmann, and Quinif, 2002; Brinkmann, et al., 2007, 2008; Argentieri, et al., 2015).

To a certain extent, the remote sensing method can provide the data necessary to guide investigations and monitoring. Thorough reconnaissance of the ground may locate sinkholes not identifiable on aerial photographs, due to their reduced size, depth, or vegetation cover.

\section{UAV Remote Sensing}

In digital photogrammetry, unmanned aerial vehicles (UAV) are a relatively new technology that can be 
used to capture digital images for large scale mapping with accuracy down to centimeter level from various waypoints for the mantled karst regions. UAV have several advantages over satellites because they can capture aerial images from certain flying height, and have flexible flying mission and timing (Anai et al., 2012; Mohd azhar et al., 2014; Yeh et al., 2016). The efficiency and high mobility of UAV makes them essential to aerial photography assisted survey and mapping.

\section{Interferometric Synthetic Aperture Radaranalysis (InSAR)}

Interferometric Synthetic Aperture Radar analysis (InSAR) can be used to screen large areas for anomalous vertical movement and to guide intensive field investigations and detection to areas where significant change is occurring (Zhao, et al., 2009; Nof, et al., 2013; Intrieri, et al., 2015; Carbonel, et al., 2015; Galve, et al., 2015). Satellites record images of the Earth's surface and these images can be combined to reveal subtle movements or deformations of the ground surface. Mapping of ground displacement may serve to identify the location of future sinkholes. There are cases in which InSAR is used to detect and characterize sinkholes, as well as for reducing the associated risk when combined with other sources of data such as a sinkhole inventory.

\section{Light detection and ranging (LiDAR)}

The light detection and ranging (LiDAR) technology is one development in the field of photogrammetry and remote sensing. Airborne LiDAR systems can measure ground and sinkhole shapes with high resolution. Acquisitions of LiDAR data for the creation of highly accurate (sub-meter) elevation models that can be used for rapid, precise detection of sinkholes. (Daniel.et al., 2013; Shaw et al., 2013).

\section{Subsurface Detection and Monitoring and Geophysical Methods}

Subsurface cavities and the processes that lead to the development of sinkholes cause changes within the subsurface (e.g., porosity, fracture density, and water saturation). Before collapse, these changes may be detected using geophysical methods (Frumkin, et al. 2011) such as ground-penetrating radar (PueyoAnchuela, et al., 2009; Lei M et al., 2007; Batayneh et al., 2002;), the direct current resistivity technique (Batayneh and Al-Zoubi 2000, Roth and Nyquist, 2003), microgravity (Eppelbaum , 2008; Alzoubi, 2013), and microtremor surveying (Rucker et al., 2013). These non-invasive measurements can be used effectively to provide reconnaissance ahead of detailed geological investigation, guide subsurface sampling and excavation, and provide continuous monitoring. The effectiveness of each geophysical technique depends on its ability to reach the target depth with the appropriate resolution in different geological settings. Therefore, integrated geophysical approaches are often reported as well as the calibration/validation with information obtained directly from boreholes.

\section{Boreholes}

Drilling provides valuable information on the nature and geotechnical properties of the ground and allow the recognition of voids and sediments disturbed by subsidence processes, including raveling zones and breccia pipes. This is a requirement for borehole data that can guide the development of an effective scope and schedule for geophysical investigations, in order to observe and verify the accuracy of predictions. However, the expensive and time-consuming technique has other limitations. The normal site investigation practice of wide-spaced boreholes means that they may easily miss cavities and raveling structures.

\section{Ground Penetrating Radar (GPR)}

Ground Penetrating Radar (GPR) is a geophysical technique that offers a very high resolution to locate and characterize structural and sedimentological information of the subsoil (such as soil-cavities, the presence of active subsidence and so on).

\section{Surface-based GPR}

In the surface-based GPR profiles this information can be identified from the change in color that is related to the amplitude of the recorded wave in each point. Soil cavities are characterized by abrupt lateral contrasts in the electromagnetic properties of the materials (Figure 1). These features are represented by hyperbolic anomalies. Structural features obtained from GPR-profiles (onlap geometries, zones with depressed reflectors, folded reflectors or laterally abrupt structural limits) can be linked to the presence of active subsidence processes without development of fully-grown cavities.
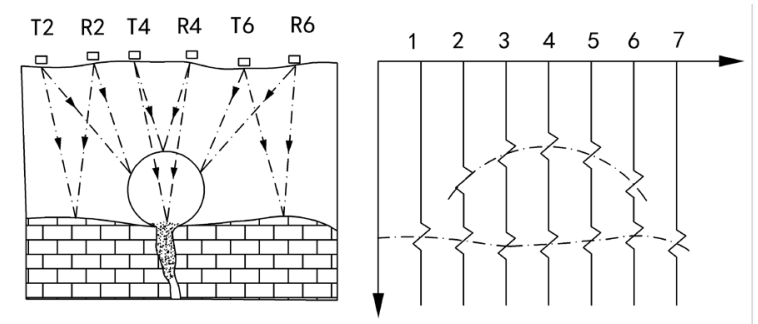

Figure 1. Soil-cavity reflections in GPR profiles. T1 T3: transmitting antenna; R1 R3: receiving antenna; 1 7: reflection waveform 


\section{Single-hole radar}

A geotechnical borehole radar technique was used to acquire high-resolution two-dimensional radar velocity data. To record single-hole full-waveform radar data, a fixed-offset transmitter receiver antenna pair is pulled slowly up the length of a borehole. Such data supply information on the velocity and attenuation of radar waves in the vicinity of the borehole and on the nature of reflectors distributed along the borehole.

The principle of the single-hole reflection method is similar to that of surface-based GPR, except that reflectors may occur on all sides of the borehole recording line (Figure 2). Planar features (such as fault surface) intersected by a borehole will appear as $\mathrm{V}$-shaped reflections on a singlehole radar section (Figure 2, b, B). The image of a point reflector (Such as soil hole) is a hyperbola (Figure 2, a, C). Due to the rotational symmetry of non-directional antennas operating in straight boreholes, the georadar data on their own do not provide sufficient information to determine unambiguously the locations of reflectors not intersected by the boreholes. To compensate for this limitation, constraints from other observations are necessary.

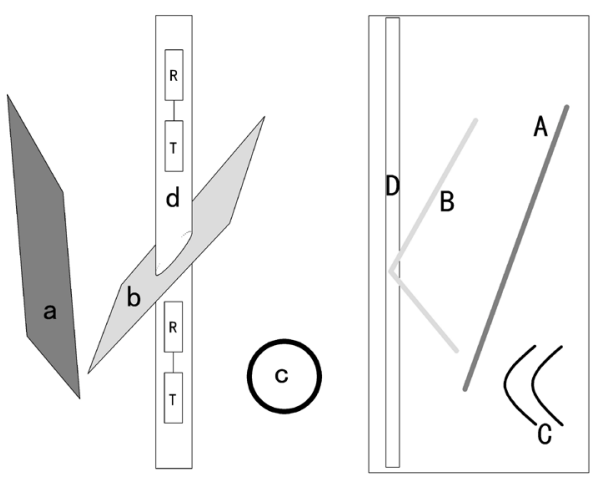

Figure 2. Single-hole radar reflection method. $a, b:$ Fracture surface; c:Karst cave; d.Borehole; $A, B$ : Reflection from Fracture surface; C: Reflection from cave; D: Direct wave; $T$ : Transmitter antenna; R: Receiving antenna.

\section{Cross-hole radar}

Cross-hole GPR is a transillumination survey method in which two antennas are lowered down in adjacent, parallel boreholes. Using two boreholes, cross-hole level scanning was performed by placing the transmitting and receiving antennas at the same distance positions in separate boreholes. By transmitting radar signals from one borehole to another, radar velocities and attenuation between the two boreholes can be estimated. The transmitter antenna emits a short pulse, or shot, of high-frequency electromagnetic energy. The receiving antenna, located in the adjacent borehole, captures the frequency-modulated signal and precisely measures the time required for the signal to travel through the ground, along the plane separating the two boreholes.

Transmission time imaging is a great way to detect the most water-filled areas (such as water-filled faults and caves), which are caused by the spread of the dielectric constant. The low speed belt represents the water filling area (Figure 3 red zone).

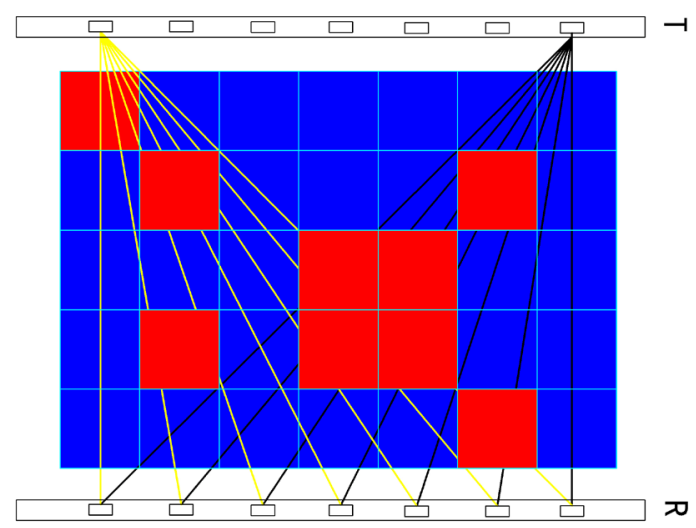

Figure 3. Crosshole GPR method. The red zone stands for water-filled faults and caves

\section{Photoelectric monitoring method}

Sinkhole collapses usually occur abruptly, so traditional land surface measurements are not very useful to forecast the occurrence of sinkhole collapses. Photoelectric sensors can play a role in precise and realtime monitoring and early warning. They may predict specific location and dimension of a potential sinkhole collapse (Lei et al. 2005).

This photoelectric monitoring method includes optical fiber sensing and coaxial cable sensing. The fiber or coaxial cable is buried underground and soil deformation is translated into strain of the fiber or cable, even up to its breakpoint. Using special measuring instruments, continuous monitoring for soil deformation and damage can be achieved for a specific site.

So, it will be a significant work to explore a way to predict the location and dimension of potential sinkholes. When embedded in sediments, optical fiber responds well to deformation of rocks and soils. It is possible to monitor soil and rock deformation by measuring the strain of optical fiber (Figure 4). Soil strain measurement using optical fibers is a promising technique for predicting karst collapse. 


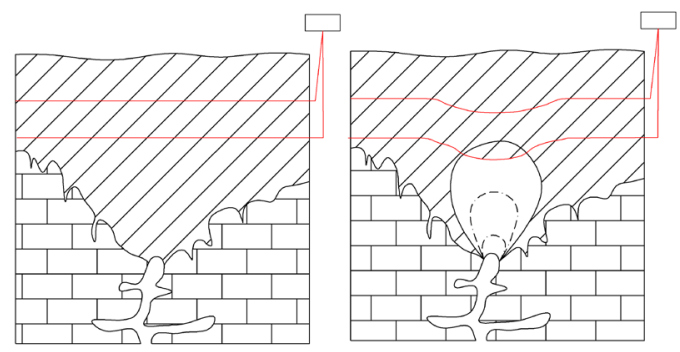

Figure 4. Photoelectric monitoring method schematic diagram. The red line stands for fiber or coaxial cable

\section{Hydrodynamic Monitoring}

Groundwater plays a key role in the development of both processes, as the agent responsible for the dissolution, and as a first order factor that determines ground instability. In fact, recent reviews reveal that a great proportion of recent sinkholes have been induced by anthropogenic changes in hydrogeological systems. There are a large number of papers that document the impact of humaninduced water table declines on sinkhole occurrence (Perez et al., 2016; Linares, et al., 2017, Jiang X et al., 2017). Groundwater-level change conductive to sinkhole collapse formation in some countries related to aquifer over-exploitation, especially in China (Lei, et al., 2016) and it plays an important role in the formation and evolution of soil caves. Groundwater levels exceeding critical values can be indicative of soil cave formation and development. The merits of this method lie in the possibility of capturing real-time changes in the underground hydrodynamic forces and in the potential for dynamic appraisal. Therefore, the monitoring of groundwater-level could become an effective method for forecasting the appearance of sinkholes (Figure 5).

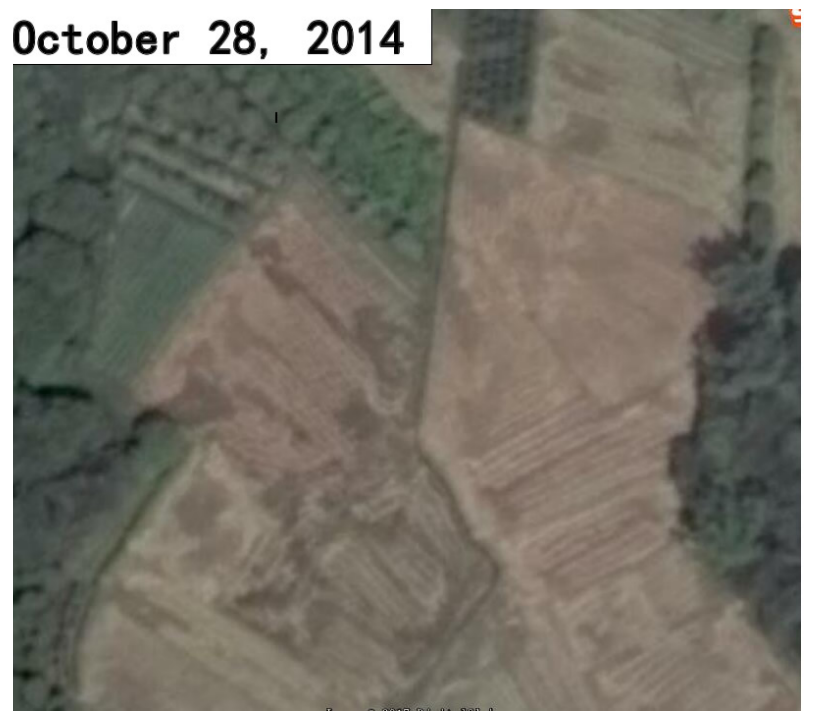

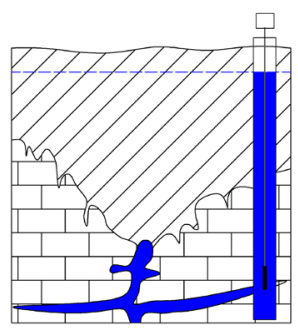

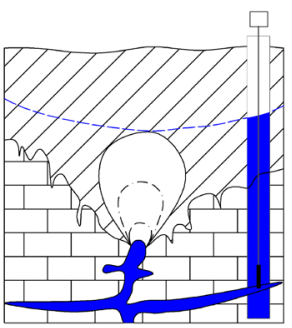

Figure 5. Hydrodynamic monitor method schematic diagram. The blue line stands for groundwater-level

\section{Case studies in the south of China Case 1: remote-sensing and Unmanned Aerial Vehicle Remote Sensing}

The study in this case has incorporated the analysis of aerial photographs from historical cartographies (2014 2016) (Figure 6) and Unmanned Aerial Vehicle Remote Sensing (2017) (Figure 7) of the studied zone in the Conghua city in the south of China. The collapse occurred between November 2014 and March 2015. A total of 47 karst collapse pits are characterized by the historical geomorphological analysis with a field inspection.

The UAV is capable of flying at low altitude together with small format digital camera and it is suitable for in the studied zone in the collapse region in the Conghua city of China. The UAV which integrated GPS has ability to perform autonomous flight and automatic navigation along planned waypoints. These waypoints are usually planned beforehand easily by dedicated software as considering the camera parameter, area of interest, overlap of image, altitude and so on. Moreover, still

\section{December 5, 2016}

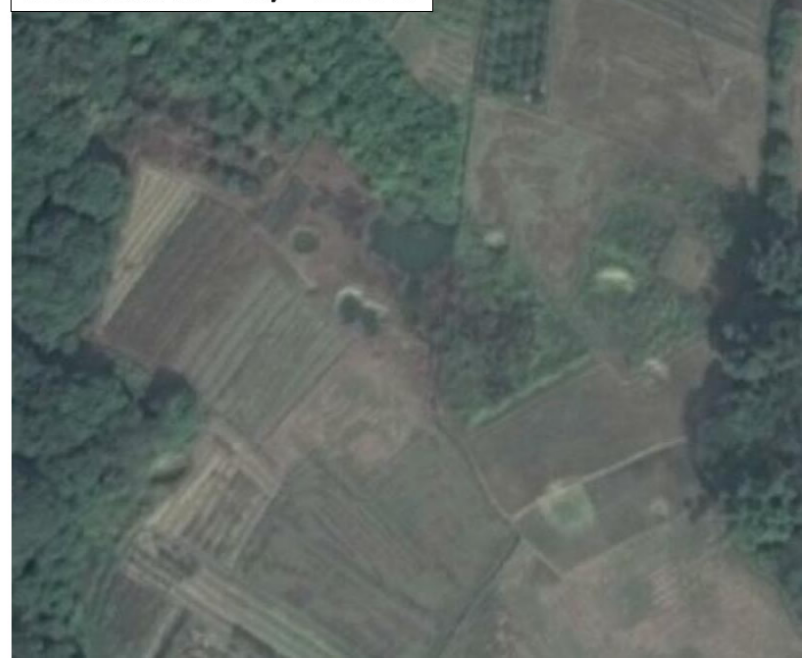

Figure 6. Historical cartographies from remote-senseing. Historical aerial photographs on October 28, 2016 and December 5, 2016. 
images at planned waypoints are acquired automatically by digital still camera mounted on UAV.

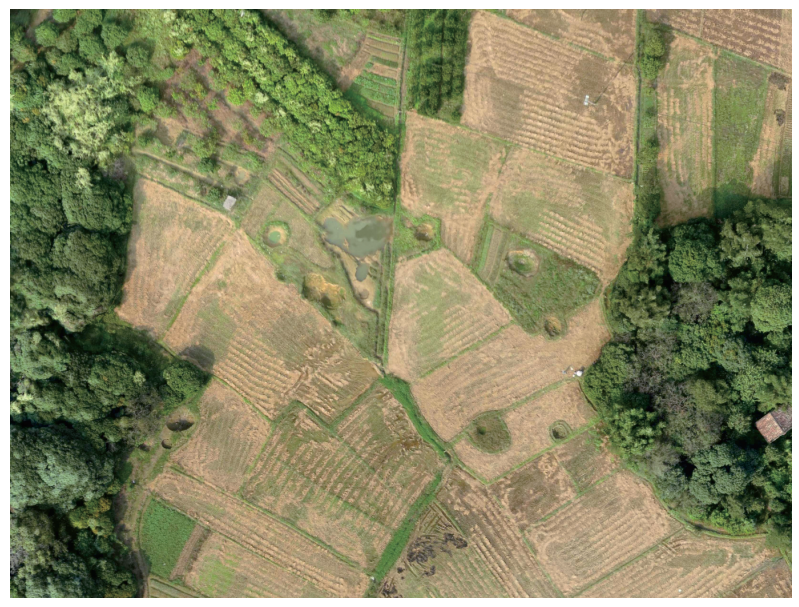

Figure 7. Example of image acquired with UAV On October 20, 2015 in the studied zone in the Conghua city of China.

\section{Case 2: InSAR and LiDAR}

Interferometric Synthetic Aperture Radaranalysis (InSAR) and Light Detection and Ranging (LiDAR) are promising technologies for monitoring the ground subsidence and characterizing sinkholes, as well as for reducing the associated risk when combined with other sources of data such as a sinkhole inventory.

In Hunan province in China, high resolution Terrasar-X satellite data is ordered (spatial resolution 3m, April 2014 - January 2015 (Figure 8). Using LiDAR data, the threedimensional model was constructed and the collapse volume was calculated (Figure 9). Through LiDAR 3D modeling, the collapse volume is more than $10,000 \mathrm{~m}^{3}$ in Hunan province.

According to work experience, InSAR and LiDAR methods should not be considered as an alternative to classical mapping methods, but a highly useful complementary approach.
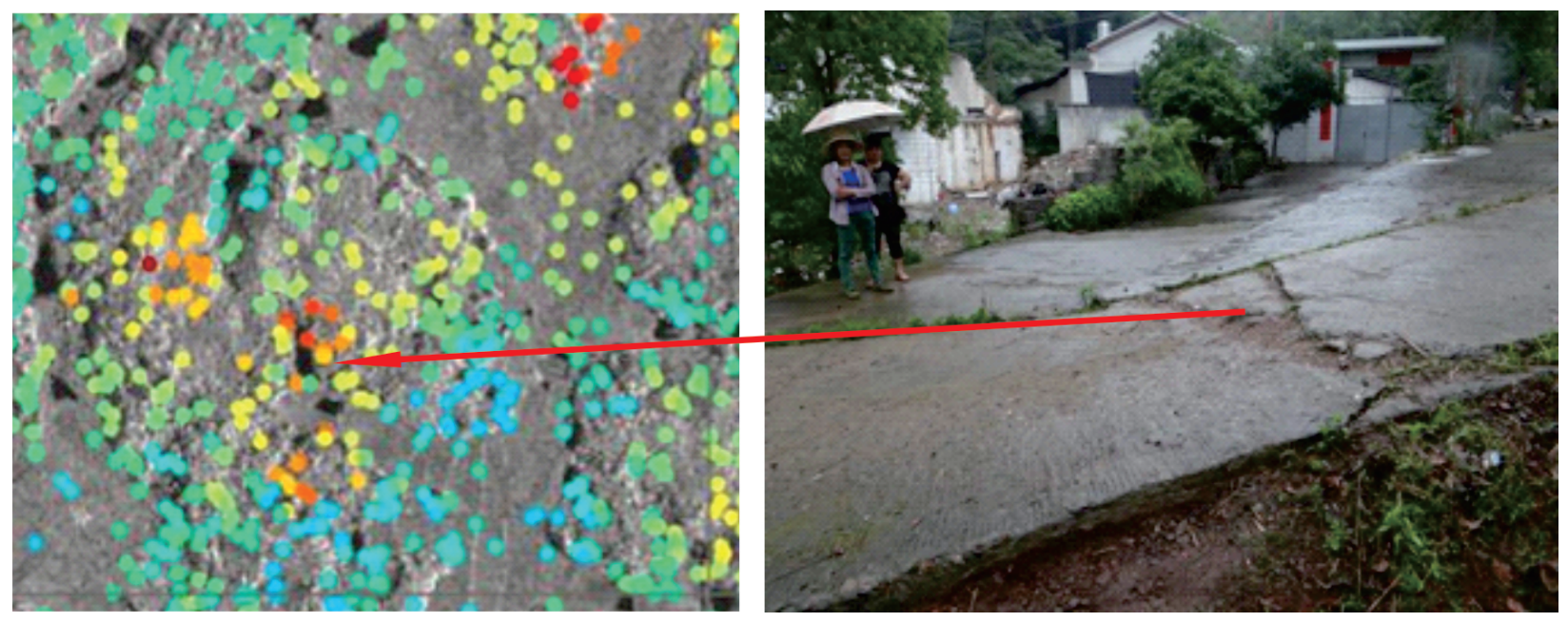

Figure 8. An example of ground subsidence points identified by InSAR data
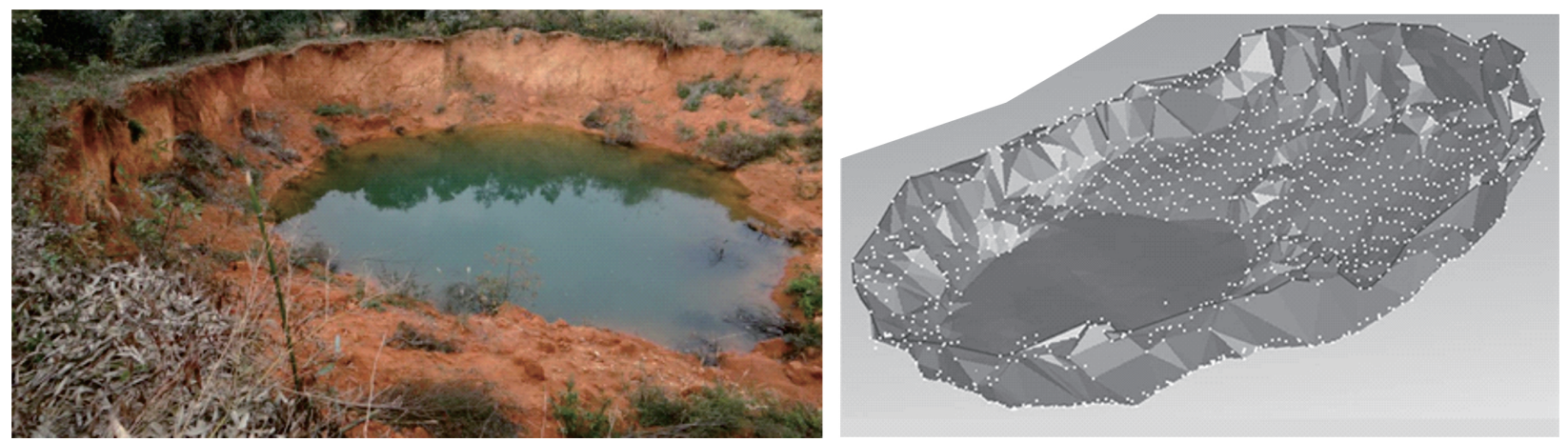

Figure 9. The photographs and the LiDAR data model for an example of a collapse pit 


\section{Case 3: Surface-based Ground Penetrating Radar (GPR)}

The main goals for GPR surveys used in this work are to locate and characterize karst hazard zones in the GuilinYangshuo highway in Guangxi, China (Lei, et al., 2011). The entire highway was built through an active karst area characterized by tower karst, karst valleys, and watershed divides. The GPR system with shielded antennas and central frequency of $100 \mathrm{MHz}$ was applied to a $12 \mathrm{~km}$ section highway to located subsurface voids in a highly active karst area (Figure 10). 337 subsurface voids, 1-6 $\mathrm{m}$ in diameter, $1-5.5 \mathrm{~m}$ deep, and density up to 48 per $100 \mathrm{~m}$, were detected using GPR.

In this work, GPR profile data processing is included sequential zero-time corrections, running average filter, exponential gain function, band-pass filter and plotting. Depending on the shape and dimensions of these cavities it is possible to find either an isolated hyperbolic anomaly, or clustering of hyperbolic anomalies.
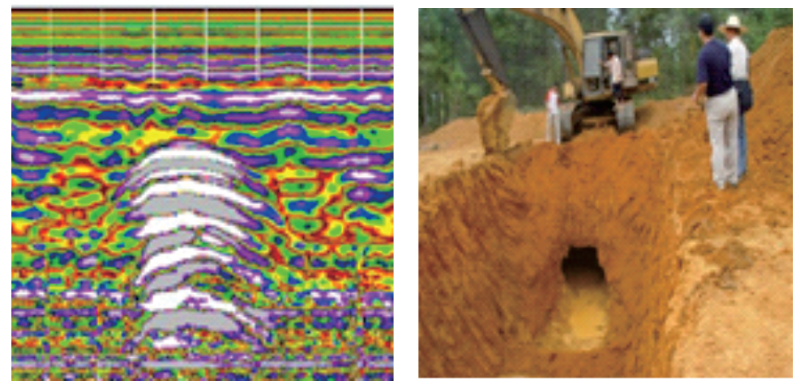

Figure 10. Left. hyperbolic anomaly in GPR profile Right. soil cavity. Results of radar collapse detection

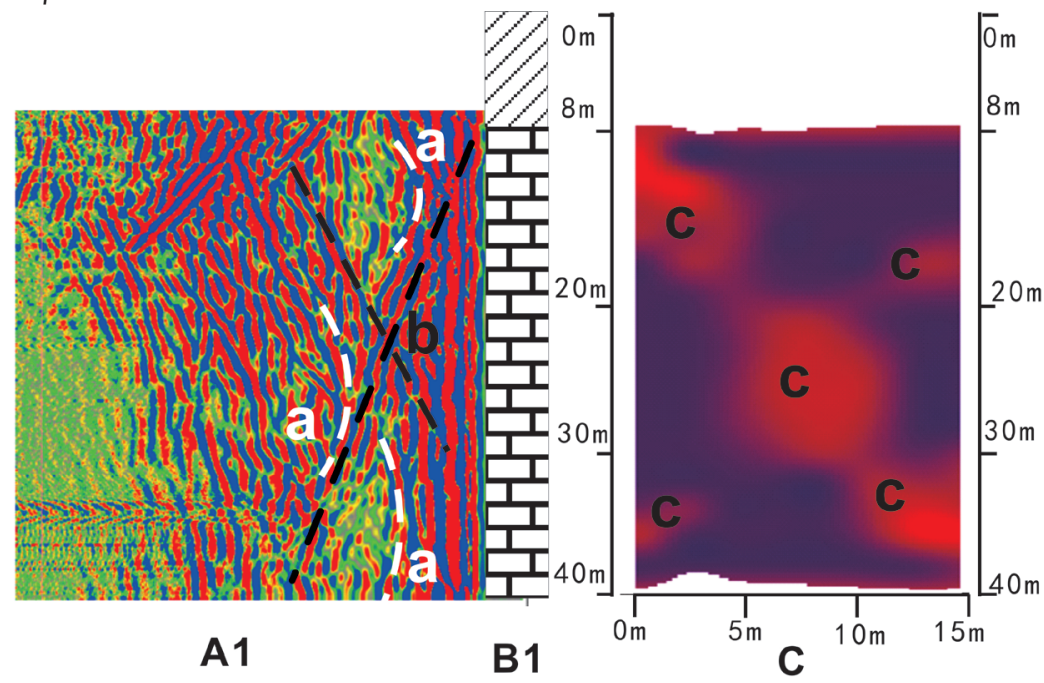

\section{Case 4: Borehole Ground Penetrating Radar (GPR)}

The Mingxin village surrounding Foshan city in southern China, drilling and borehole radar is employed to detect deep karst activity in this study. A 15 meter deep water filled karst cave with a diameter of about 6 meters was found at the test site (Figure 11), using borehole radar $(100 \mathrm{MHz})$. Earlier, it was not detected by drilling.

\section{Case 5: Photoelectric monitoring methods}

The photoelectric monitoring method is employed for monitoring and predicting potential sinkholes by the Institute of Karst Geology in China. Two pilot monitoring sites were established in 2006 and 2012 at Guilin and Guigang of Guangxi province to monitor potential sinkholes along the highway and the oil pipe, respectively (Figure 12) (Jiang, et al, 2016).

\section{Case 6: Hydrodynamic monitoring}

In areas susceptible to sinkhole collapse in the Guangzhou city of China, changes in groundwater level are monitored for early warning purposes. Figure 13 shows that historic sinkholes and groundwater-level changes are closely correlated with groundwater pumping related to underground construction. Before February 2, 2008, because of groundwater withdrawal in this area, the groundwater level at the well declined to an elevation of $1.50-1.88 \mathrm{~m}$. Concurrently, in the surrounding regions, six large sinkhole collapses occurred and the underground construction was suspended. By February 18, 2008, the water level had risen gradually to an elevation of 4.10 $\mathrm{m}$ and no further ground collapses had occurred. By September 17, 2008, the underground water level had

Figure 11. Borehole GPR survey and its results. A 1,A2: Single-hole radar profile; B1,B2: bore histogram; C: crosshole radar profile; a: hyperbolic anomalies; b: line anomalies c: the low speed zone representing the water filling area (water-filled faults and caves); 

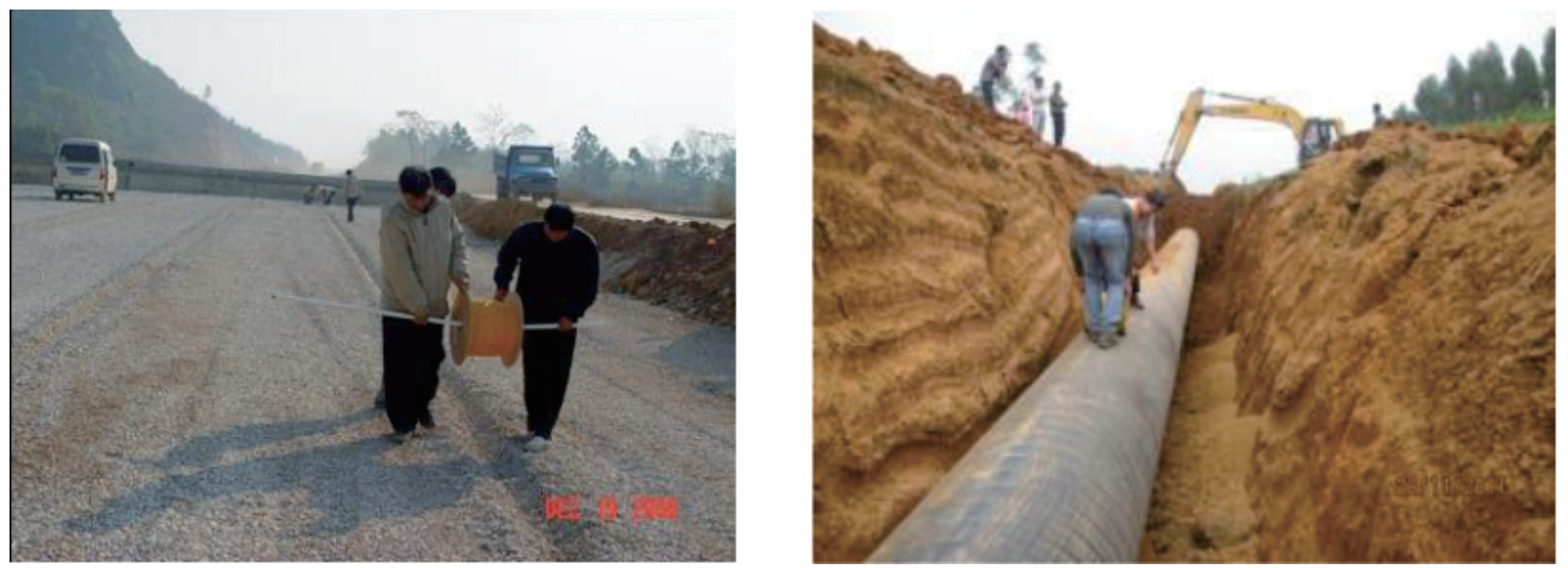

Figure 12. Photoelectric monitoring along the highway and the oil pipe

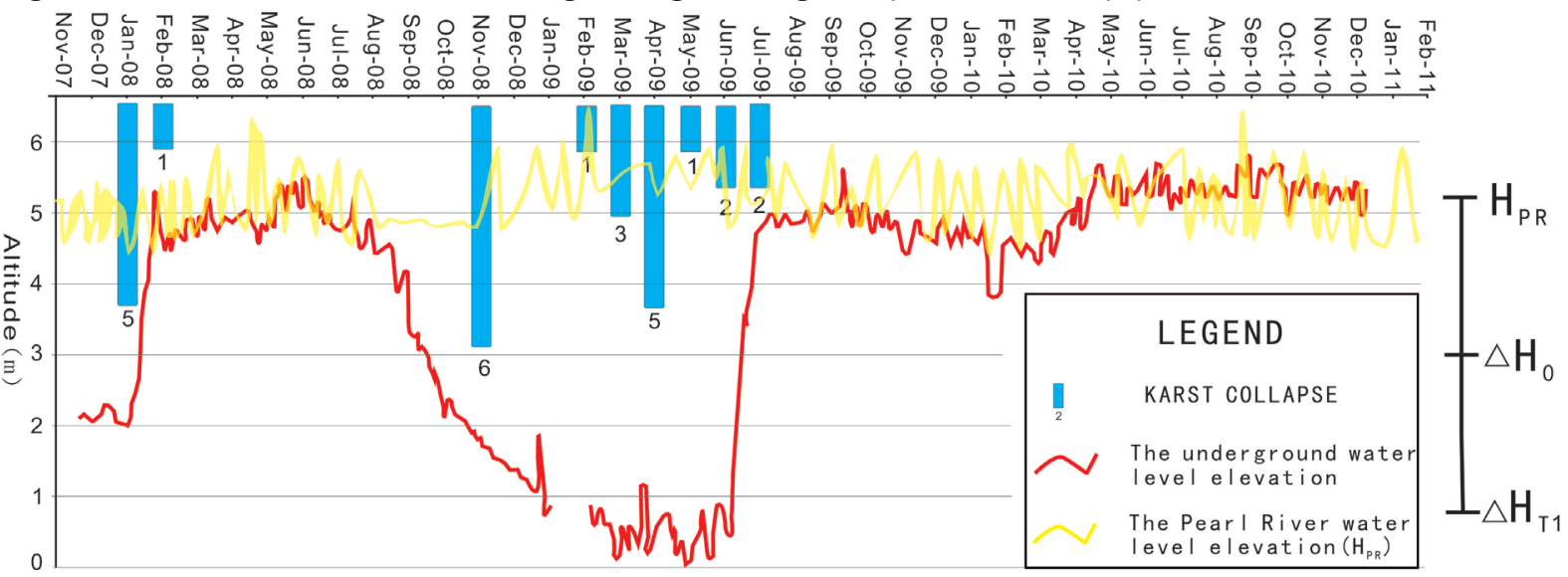

Figure 13. The groundwater-level data from monitoring well

again begun to decline. During this period, 12 further sinkhole collapses occurred, which were concurrent with the groundwater pumping activities.

\section{Conclusions}

Commonly, cover-collapse sinkhole may have a very subtle geomorphic expression or the collapse created by underground processes may not yet have reached the ground surface. It is essential to investigate as many sources of surface and subsurface information as possible to provide data about the past and current subsidence activity in the study area. The presence of active subsidence, soil-cavities and the changes of groundwater level can be used as indicators of active karst processes and karst geologic hazard. This study aims at developing a methodological framework for imaging common surface, subsurface and hydrodynamic features.

(1) Sinkholes are commonly mapped using conventional geomorphological methods like field surveys, aerial photographs and topographic maps. Unmanned Aerial Vehicle Remote (UAV), LiDAR systems and satellite images photographs, especially large-scale stereoscopic images with high resolution, are very useful tools for identifying sinkholes. The geomorphological interpretations help to obtain minimum estimates of the probability of sinkhole occurrence and allow the analysis of the spatio-temporal distribution patterns of the subsidence phenomena. However, the effectiveness of this approach may be quite limited in areas where the geomorphic expression of sinkholes has been obliterated by natural processes or anthropogenic fill.

In addition, InSAR, under favorable conditions, allows the measurement of sub-centimetric deformation occurring over time spans of days or years, covering extensive areas with a high temporal and spatial resolution and without the need of conducting field work. So InSAR can be used to monitor surface subsidence prior to collapse.

(2) Sinkhole collapses usually occur abruptly without any the surface obvious indications. These reasons traditional land surface survey and measurements are not very useful to forecast the occurrence of sinkhole 
collapses. Soil strain measurement using optical fibers is a promising technique for predicting karst collapse.

Geophysical methods also have been widely used for the study of sinkholes and the detection of the underground voids linked to their development or to identify and outline, within larger areas, the zones most susceptible to sink. Geophysical methods, specially ground Penetrating Radar (GPR), usually non-destructive and performed from the ground surface, offer a means by which to investigate the soil mass between borings or soundings in a more continuous manner. Although geophysical methods help characterize the soil mass between borings or soundings, ambiguous interpretation and a lack of engineering properties have limited their usage in the past.

Boreholes allow calibrating and validating the geophysical investigations. Drilling provide valuable information on the nature and geotechnical properties of the ground and allow the recognition of voids and sediments disturbed by subsidence processes. The drilling is the expensive and time-consuming technique, may easily miss cavities. To compensate for this limitation, the geotechnical borehole radar technique can be a complementary technique.

(3) Understanding the hydrogeology of the study area is a crucial aspect of sinkhole hazard analysis. Water monitoring was aimed at identifying the relation between the groundwater level fluctuations and the sinkhole activity. The position of the groundwater table and its fluctuations through time and space, obtained primarily by using long-term piezometric data, is essential to estimate the groundwater flow patterns and the development of the depression causes, which may play a fundamental role in the formation of sinkholes.

(4) These kinds of techniques and methods can be combined to form a comprehensive system for identifying hidden danger of karst collapse, understanding the causes of the deformation, assessing the kinematics of the cover-collapse sinkhole.

\section{Acknowledgments}

This work was funded by the Project of the China Geological Survey (Nos. DD20160254, 12120115044601), and the National Natural Science Foundation (Nos. 41402284, 41472298, 41302255);

\section{References}

Alzoubi A, Abueadas E, Akawwi E, Eppelbaum L, Levi E, Ezersky, M. 2013. Use of microgravity survey in the Dead Sea areas affected by the sinkholes hazard. Assembly of the European Union of Geosciences (14: 1982).

Anai T, Sasaki T, Osaragi K, Yamada M, Otomo F, Otani H. 2012. Automatic exterior orientation procedure for low-cost UAV photogrammetry using video image tracking technique and GPS information. ISPRS - International Archives of the Photogrammetry, Remote Sensing and Spatial Information Sciences, XXXIX-B7, 469-474.

Argentieri A, Carluccio R, Cecchini F, Chiappini M, Ciotoli G, Ritis R D. 2015. Early stage sinkhole formation in the Acque Albule basin of central Italy from geophysical and geochemical observations. Engineering Geology, 191, 36-47.

Awni t. Batayneh, Abueladas AA, Moumani K A. 2002. Use of ground-penetrating radar for assessment of potential sinkhole conditions: an example from Ghor al Haditha area, Jordan. Environmental Geology, 41(8), 977-983.

Batayneh A, Al-Zoubi A, 2000. Detection of a solution cavity adjacent to a highway in southwest Jordan using electrical resistivity methods. Environ Eng Geophys 5:25-30.

Beck, B. 2012. Soil piping and sinkhole failures. Encyclopedia of Caves, 718-723.

Brinkmann R, Wilson, K., Elko, N., Seale, LD, Florea L, Vacher HL. 2007. Sinkhole distribution based on pre-development mapping in urbanized Pinellas County, Florida, USA.

Brinkmann, R., Parise, M., Dye, D., 2008. Sinkhole distribution in a rapidly developing urban environment: Hillsborough County, Tampa Bay area, Florida. Engineering Geology. 99,169-184.

Geological Society London Special Publications, 279,511.

Carbonel D, Rodríguez-Tribaldos V., Gutiérrez F, Galve JP, Guerrero, J. Zarroca, M. 2015. Investigating a damaging buried sinkhole cluster in an urban area (Zaragoza city, NE Spain) integrating multiple techniques: geomorphological surveys, dinsar, dems, gpr, ert, and trenching. Geomorphology, 229, 3-16.

Doctor DH, Young JA. 2013. An Evaluation Of Automated GIS tools for delineating karst sinkholes and closed depressions from 1-meter lidar-derived digital elevation data. Proceedings of the Thirteenth Multidisciplinary Conference on Sinkholes and the Engineering and Environmental Impacts of Karst, p449-458.

Eppelbaum LV, Ezersky M, Alzoubi A, Goldshmidt, V, Legchenko A. 2008. Study of the factors affecting the karst volume assessment in the dead sea sinkhole problem using microgravity field analysis 
and 3-d modeling. Advances in Geosciences, 19, 97-115.

Forth RA, Butcher D, Seniorc R. 1999. Hazard mapping of karst along the coast of the Algarve, Portugal. Engineering Geology. 52(1-2), 67-74.

Frumkin A, Ezersky M, Al-Zoubi A, Akkawi E, Abueladas AR. 2011. The Dead Sea sinkhole hazard: geophysical assessment of salt dissolution and collapse. Geomorphology, 134(1-2), 102-117.

Galve J P, Gutiérrez F, Remondo J, Bonachea J, Lucha, P, Cendrero A. 2009. Evaluating and comparing methods of sinkhole susceptibility mapping in the ebro valley evaporite karst (NE Spain). Geomorphology, 111(3-4), 160-172.

Galve JP, Castañeda C, Gutiérrez F, Herrera, G. 2015. Assessing sinkhole activity in the Ebro Valley mantled evaporite karst using advanced dinsar. Geomorphology, 229, 30-44.

Gutiérrez F, Guerrero J, Lucha P. 2008. A genetic classification of sinkholes illustrated from evaporite paleokarst exposures in Spain. Environmental Geology, 53(5), 993-1006.

Gutiérrez F, Parise M, De Waele J, Jourde, H. 2014. A review on natural and human-induced geohazards and impacts in karst. Earth-Science Reviews. 138, 61-88.

Intrieri E, Gigli G, Nocentini M, Lombardi L, Mugnai F, Fidolini F, Casagli N. 2015. Sinkhole monitoring and early warning: an experimental and successful GB-InSAR application. Geomorphology, 241(241), 304-314.

Jiang X, Gao Y, Wu, Y, Lei M. 2016. Use of brillouin optical time domain reflectometry to monitor soilcave and sinkhole formation. Environmental Earth Sciences, 75(3), 1-8.

Jiang X, Lei, M, Gao, Y, Jiang, X, Lei, M, Gao Y. 2017. New karst sinkhole formation mechanism discovered in a mine dewatering area in Hunan, China. Mine Water \& the Environment, 2017, 22(2): 186-190.

Kaufmann O, Quinif Y. 2002. Geohazard map of cover-collapse sinkholes in the 'Tournaisis' area, southern Belgium. Engineering Geology, 65(2-3), 117-124.

Lei, M., Gao, Y., Li, Y., Meng, Y., Yu, L., \& Gan, F. 2008. Detection and treatment of sinkholes and subsurface voids along Guilin-Yangshuo Highway, Guangxi, China. In; Yuhr LB, Alexander EC Jr., Beck BF, editors, Sinkholes and the Engineering and Environmental Impacts of Karst, Proceedings of the 11th Multidisciplinary Conference on Sinkholes and the Engineering and Environmental Impacts of Karst, ASCE, p. 632-639).

Linares R, Roqué C, Gutiérrez F, Zarroca M, Carbonel
D, Bach, J. 2017. The impact of droughts and climate change on sinkhole occurrence. a case study from the evaporite karst of the fluvial valley, NE Spain. Science of the Total Environment, 579, 345-358.

Rucker M, Hulburt S, Edwards M. 2013.

Reconnaissance evaluation of a potential future sinkhole using integrated simple surface geophysics and surface monitoring points. In: Land L, Doctor DH, Stephenson JB, editors, National Cave and Karst Research Institute Symposium 2, Proceedings of the 13th Multidisciplinary Conference on Sinkholes and the Engineering and Environmental Impacts of Karst, p. 221-229.

Melinda G. Shaw Faulkner, Kevin W. Stafford, Aaron W. Bryant, 2013. Delineation and Classification of Karst Depressions Using LiDAR: Fort Hood Military Installation, Texas. In: Land L, Doctor DH, Stephenson JB, editors, National Cave and Karst Research Institute Symposium 2, Proceedings of the 13th Multidisciplinary Conference on Sinkholes and the Engineering and Environmental Impacts of Karst, p. 459-567

Mohd Azhar NA, Ahmad A. 2014. Development of rapid \& low cost archaeological site mapping using photogrammetric technique. IOP Conference Series: Earth and Environmental Science (18, p.012032).

Pueyo-Anchuela, O, Pocovi Juan A, Soriano AM, Casas-Sainz AM. 2009. Characterization of karst hazards from the perspective of the doline triangle using GPR - examples from central Ebro Basin (Spain). Engineering Geology, 108(3-4), 225-236.

Parise M, Vennari C. 2013. A chronological catalogue of sinkholes in Italy: The first step toward a real evaluation of the sinkhole hazard. In: Land L, Doctor DH, Stephenson JB, editors, National Cave and Karst Research Institute Symposium 2, Proceedings of the 13th Multidisciplinary Conference on Sinkholes and the Engineering and Environmental Impacts of Karst, p. 383-392.

Perez AL, Nam BH, Alrowaimi M, Chopra M, Lee SJ, Youn H. 2016. Experimental study on sinkholes: soil-groundwater behaviors under varied hydrogeological conditions. Journal of Testing \& Evaluation, 45(1), 20160166.

Nof RN, Baer G, Ziv A, Raz E, Atzori S, Salvi S. 2013. Sinkhole precursors along the dead sea, Israel, revealed by SAR interferometry. Geology, 41(9), 1019-1022.

Roth MJS, Nyquist JE. 2003. Evaluation of multielectrode earth resistivity testing in karst. 
Geotechnical Testing Journal, 26(2), 167-178.

Waltham T, Bell FG, Culshaw M. 2005. Sinkholes and subsidence: karst and cavernous rocks in engineering and construction. Berlin, Springer, $382 \mathrm{p}$.

Yeh ML, Chou YT, Yang, LS. 2016. The evaluation of GPS techniques for UAV-based photogrammetry in urban area. ISPRS - International Archives of the Photogrammetry, Remote Sensing and Spatial Information Sciences, XLI-B1, 1079-1084.

Zhao Q, Lin H, Jiang L, Chen F, Cheng S. 2009. A study of ground deformation in the Guangzhou urban area with persistent scatterer interferometry. Sensors, 9(1), 503-18. 